\title{
Consumption Habits and Humps
}

\author{
Kraft, Holger; Munk, Claus; Seifried, Frank Thomas; Wagner, Sebastian
}

Document Version

Accepted author manuscript

Published in:

Economic Theory

DOI:

10.1007/s00199-016-0984-1

Publication date:

2017

License

Unspecified

Citation for published version (APA):

Kraft, H., Munk, C., Seifried, F. T., \& Wagner, S. (2017). Consumption Habits and Humps. Economic Theory, 64(2), 305-330. https://doi.org/10.1007/s00199-016-0984-1

Link to publication in CBS Research Portal

\section{General rights}

Copyright and moral rights for the publications made accessible in the public portal are retained by the authors and/or other copyright owners and it is a condition of accessing publications that users recognise and abide by the legal requirements associated with these rights.

Take down policy

If you believe that this document breaches copyright please contact us (research.lib@cbs.dk) providing details, and we will remove access to the work immediately and investigate your claim. 


\section{Consumption Habits and Humps}

Holger Kraft, Claus Munk, Frank Thomas Seifried, and Sebastian Wagner

Journal article (Accepted version)

CITE: Consumption Habits and Humps. / Kraft, Holger; Munk, Claus; Seifried, Frank

Thomas; Wagner, Sebastian. In: Economic Theory, 13.06.2016.

The final publication is available at Springer via

http://dx.doi.org/10.1007/s00199-016-0984-1

Uploaded to Research@CBS: June २०17 


\title{
Consumption Habits and Humps
}

\author{
Holger Kraft • Claus Munk • Frank \\ Thomas Seifried • Sebastian Wagner
}

\begin{abstract}
We show that the optimal consumption of an individual over the life cycle can have the hump shape (inverted U-shape) observed empirically if the preferences of the individual exhibit internal habit formation. In the absence of habit formation, an impatient individual would prefer a decreasing consumption path over life. However, because of habit formation, a high initial consumption would lead to high required consumption in the future. To cover the future required consumption, wealth is set aside, but the necessary amount decreases with age which allows consumption to increase in the early part of life. At some age, the impatience outweighs the habit concerns so that consumption starts to decrease. We derive the optimal consumption strategy in closed form, deduce sufficient conditions for the presence of a consumption hump, and characterize the age at which the hump occurs. Numerical examples illustrate our findings. We show that our model can quantitatively reproduce
\end{abstract}

\footnotetext{
We appreciate comments from James Feigenbaum, Nicola Fuchs-Schündeln, Michael Haliassos, Tim Kehoe, Natalia Khorunzhina, Christian Laux, Mirko Wiederholt, and participants at presentations at the Swiss Society for Financial Market Research, the University of York, the Vienna University of Economics and Business, and the Copenhagen Business School. Holger Kraft and Sebastian Wagner gratefully acknowledge financial and research support from the Center of Excellence SAFE, funded by the State of Hessen initiative for research LOEWE. Holger Kraft and Sebastian Wagner gratefully acknowledge financial support by Deutsche Forschungsgemeinschaft (DFG).

Holger Kraft

Department of Finance, Goethe University Frankfurt am Main, Faculty of Economics and Business Administration, Germany, E-mail: holgerkraft@finance.uni-frankfurt.de

Claus Munk

Department of Finance, Copenhagen Business School, Denmark, E-mail: cm.fi@cbs.dk

Frank Thomas Seifried

Department IV - Mathematics, University of Trier, Germany, E-mail: seifried@uni-trier.de

Sebastian Wagner

Department of Finance, Goethe University Frankfurt am Main, Faculty of Economics and Business Administration, Germany, E-mail: Sebastian.Wagner@hof.uni-frankfurt.de
} 
the hump observed in U.S. consumption data from the Consumer Expenditure Survey.

Keywords Consumption hump · life-cycle utility maximization · habit formation · impatience

JEL classification D91 D11 D14

\section{Introduction}

Starting with Thurow (1969) numerous empirical studies have documented that the consumption expenditures of individuals typically have an inverted U-shape over the life cycle by being increasing up to age 45-50 years and then decreasing over the remaining life. ${ }^{1}$ Standard, frictionless consumption-savings models cannot generate such a hump in consumption, and the existing literature explains the hump by various frictions or non-hedgeable risks (see below). This paper shows that the consumption hump naturally emerges, even in the absence of frictions or risks, when the preferences of the individual exhibit habit formation instead of the time additivity typically assumed. Our parsimonious model can quantitatively match the life-cycle consumption pattern observed in the U.S. Consumer Expenditure Survey (CEX).

How can habit formation induce a hump in life-cycle consumption? In a standard, frictionless consumption-saving model with time-additive utility the life-cycle consumption pattern is determined by the relation between the subjective time preference rate $\delta$ of the individual and the (risk-adjusted expected) return $r$ on investments. ${ }^{2}$ If $\delta=r$, the consumption profile is flat over the life cycle. If $\delta>r[\delta<r]$, the consumption profile is decreasing [increasing] over the entire life time. With enduring habits for consumption, the price of consumption is effectively decreasing over life. An increase in consumption early in life amplifies the desire for increased consumption throughout the remaining life time and thus a significant increase in the present value of future expenditures. Later in life, an increase in consumption is less costly because it only increases expenditures over a shorter remaining life time. Therefore habit formation motivates the agent to lower consumption early in life and, financed by the additional savings, increase consumption towards the end of life. In the case where $\delta>r$, the declining consumption profile with time-additive utility can thus become hump shaped when habit formation is introduced.

We illustrate this mechanism in the simplest possible model with full certainty and no frictions. The individual is equipped with some initial wealth that can be invested at a constant risk-free rate. The individual can continuously

\footnotetext{
1 Later studies using different data sources and periods confirm this pattern, see, e.g., Attanasio and Weber (1995), Attanasio, Banks, Meghir, and Weber (1999), Browning and Crossley (2001), Gourinchas and Parker (2002), and Fernández-Villaverde and Krueger (2007).

2 The life-cycle consumption-saving theory builds on work by Ramsey (1928), Fisher (1930), Modigliani and Brumberg (1954), and Friedman (1957) and was extended to rigorously incorporate uncertainty by Samuelson (1969) and Merton (1969, 1971).
} 
withdraw funds for consumption. Our main model assumes that (i) the agent has a concave power utility function of the difference between consumption and the habit level at that time and (ii) the habit level is a scaled, exponentially weighted average of past consumption rates of the individual. Under these assumptions, we derive a closed-form solution for the optimal consumption plan as well as a set of sufficient parameter conditions for the presence of a consumption hump.

We calibrate our model to 1980-2003 CEX consumption data and find that the model matches very well the observed hump-shaped consumption pattern of both singles and couples for reasonable parameter values. We illustrate how the consumption profile and the location of the hump are affected by key model parameters. For example, we find that the bigger the impact of current consumption on future habit levels, the later the consumption hump occurs. Moreover, consumers who are very impatient or have a low utility curvature parameter have a consumption profile peaking at a relatively young age.

As a robustness check, we solve numerically for the optimal consumption plan under alternative habit specifications. We show that the consumption profile can be hump shaped also when the habit enters the utility function multiplicatively or when the habit is specified in terms of past log-consumption. These results indicate that the consumption hump is caused by the presence of habit formation and not its precise implementation.

Known explanations of the consumption hump include borrowing constraints (Thurow 1969), income uncertainty and precautionary savings (Nagatani 1972; Carroll 1997; Gourinchas and Parker 2002), endogenous labor supply with hump-shaped wages (Becker 1965; Heckman 1974), variations in household size (Attanasio and Browning 1995; Browning and Ejrnæs 2009), mortality risk (Feigenbaum 2008; Hansen and İmrohoroğlu 2008), late-life health concerns (Domeij and Johannesson 2006), and consumer durables serving as collateral (Fernández-Villaverde and Krueger 2011). Our purpose is not to question these explanations but rather to add a new, simple explanation of the hump. The formal models in the above-listed papers are all built on the maximization of time-additive utility of one good or two goods (with leisure or durables as the second good). The constraints, collateral, unspanned income risk, and mortality risk in these models make it difficult to derive the optimal consumption strategy in closed form. We show that habit formation in itself offers a transparent explanation of the consumption hump, and even our very parsimonious model matches the observed consumption hump nicely. These findings strongly suggest that an improved fit to the observed consumption pattern can be obtained by adding habit formation to a model with some of the above-listed hump-generating features.

The consumption hump appears in our model only if $\delta>r$. Indeed, numerous experimental studies estimate the subjective time preference rate of individuals to be around 10\% per year or even higher (Andersen, Harrison, Lau, and Rutström 2008). Habit formation has a long history in economics and finds empirical support (Carrasco, Labeaga, and Lopez-Salido 2005; Browning 
and Collado 2007; Ravina 2007). ${ }^{3}$ Regarding the consequences of habit formation for individual decision making, the literature has so far focused on the portfolio choice implications (Ingersoll 1992; Munk 2008), and Betermier, Calvet, and Sodini (2015) observe that habit formation can explain some of the patterns observed in the portfolio decisions of Swedish households. In contrast to these papers, we study the implications of habit formation for consumption over the life cycle.

The habit in our model is internal in the sense that it is formed by the agent's own past consumption choices. In an equilibrium asset pricing context, consumption habits are often assumed to be external, e.g., determined by the consumption choices of peers ("keeping up with the Joneses") or the per capita consumption in the economy. Habit features in representative agent preferences have proven helpful in explaining stylized asset pricing facts that seem puzzling using time-separable power utility, see, e.g., Abel (1990), Constantinides (1990), Campbell and Cochrane (1999), and Menzly, Santos, and Veronesi (2004), although Lettau and Uhlig (2000) and Pijoan-Mas (2007) question the success of these models. Based on an endowment economy with identical agents, Grischenko (2010) concludes that an internal habit specification, as we employ, provides a better match with asset pricing data than an external habit specification. Heaton (1995) and Chen and Ludvigson (2009) report similar results. In a steady-state equilibrium of a growth economy, Diaz, Pijoan-Mas, and Rios-Rull (2003) find that persistent consumption habits lead to higher precautionary savings and less inequality in the wealth distribution across households compared to standard, non-habit preferences. Habit formation is also used in other areas of macroeconomics, see, e.g., Carroll, Overland, and Weil (2000), Boldrin, Christiano, and Fisher (2001), and Del Negro, Schorfheide, Smets, and Wouters (2007). Fuhrer (2000) and Christiano, Eichenbaum, and Evans (2005) show that habit formation may explain the hump-shaped response over time of aggregate consumption to a monetary policy shock. In contrast, we show that habit formation may lead to consumption being hump-shaped over the life of an individual.

The rest of the paper is organized as follows. Section 2 states the model and provides a closed-form solution for the optimal consumption plan. Analytical results on the existence and location of the consumption hump are established in Section 3. The calibration of the model to U.S. consumption data is presented in Section 4. Section 5 discusses the sensitivity of the results with respect to the values of key parameters. Section 6 contains the results for alternative specifications of the habit and its utility effect. Finally, Section 7 concludes. All proofs are relegated to appendices.

\footnotetext{
3 According to Browning (1991), the idea of intertemporally non-separable preferences dates back to the 1890 book "Principles of Economics" by Alfred Marshall. The consequences of habit formation have been studied formally at least since Ryder and Heal (1973).
} 


\section{The model}

We set up a deterministic, continuous-time model of an individual's life-cycle consumption and savings decisions. The individual enters the economy at time 0 with some initial wealth $X_{0}$ and lives until time $T>0$, which we assume is a known constant. The individual consumes a single consumption good with $c(t)$ representing the consumption rate at time $t$, so that the number of goods consumed over a short interval $[t, t+d t]$ is approximately $c(t) d t$. The good is the numeraire in the economy. The wealth not spent on consumption is invested in a savings account that offers a constant, risk-free rate of $r$, continuously compounded. The individual receives no other income during life than the interest on savings. ${ }^{4}$ The dynamics of wealth $X(t)$ is then simply

$$
d X(t)=r X(t) d t-c(t) d t
$$

The individual has to determine a consumption strategy $(c(t))_{t \in[0, T]}$, which in our deterministic setting is simply a function $c:[0, T] \mapsto \mathbb{R}$.

We assume that the preferences of the individual exhibit (internal) habit formation. As standard in continuous-time formulations (e.g., Constantinides 1990), we define the time $t$ habit level to be

$$
h(t)=h_{0} e^{-\beta t}+\alpha \int_{0}^{t} e^{-\beta(t-s)} c(s) d s,
$$

where $h_{0}, \alpha$, and $\beta$ are non-negative constants. The last term is proportional to a weighted average of past consumption where we can interpret $\beta$ as a persistence parameter and $\alpha$ as a scaling parameter. Finally, $h_{0} \geq 0$ is an initial habit level whose influence fades away over time provided that $\beta>0$. Note that the habit level evolves as

$$
d h(t)=(\alpha c(t)-\beta h(t)) d t .
$$

Given a wealth of $x$ and a habit level of $h$ at time $t$, the individual is assumed to evaluate a given consumption strategy $c=(c(s))_{s \in[t, T]}$ over the remaining life by

$$
J^{c}(t, x, h)=\int_{t}^{T} e^{-\delta(s-t)} U(c(s)-h(s)) d s+\varepsilon e^{-\delta(T-t)} U(X(T)),
$$

where $\delta$ is a constant subjective time preference rate, $\varepsilon \geq 0$ is a constant indicating the preference weight of the bequest $X(T)$ relative to consumption, and

$$
U(z)=\frac{1}{1-\gamma} z^{1-\gamma}
$$

\footnotetext{
4 We could easily incorporate a deterministic labor income stream. In an unrestricted, complete market model an income stream can be replaced by its unique present value. Hence, labor income has distinct effects on optimal consumption and savings decisions only in the presence of income uncertainty which is unspanned by traded assets or if the agent faces potentially binding borrowing constraints.
} 
We refer to $\gamma$ as the utility curvature parameter and assume that $\gamma>1 .^{5}$ This is a standard representation of consumption habits in preferences (e.g., Constantinides 1990, Campbell and Cochrane 1999, Chen and Ludvigson (2009)). The indirect utility function is defined as

$$
J(t, x, h)=\max _{c} J^{c}(t, x, h) .
$$

The setup requires that consumption stays above the habit level, otherwise the marginal utility would be infinite. This implies that wealth at any point in time has to be sufficient to finance future minimum consumption. If the individual has a time $t$ habit level of $h(t)$ and consumes at the minimum level (i.e., the habit level) in all future so that $c(s)=h(s)$, the habit level evolves as $d h(s)=-(\beta-\alpha) h(s) d s$ which implies that

$$
h(s)=e^{-(\beta-\alpha)(s-t)} h(t), \quad s \in[t, T] .
$$

The time $t$ present value of this stream of minimum future consumption is

$$
\int_{t}^{T} e^{-r(s-t)} h(s) d s=h(t) A(t)
$$

where

$$
A(t)= \begin{cases}T-t & \text { if } r_{A}=0 \\ \frac{1}{r_{A}}\left(1-e^{-r_{A}(T-t)}\right) & \text { otherwise }\end{cases}
$$

with

$$
r_{A}=r+\beta-\alpha .
$$

The difference $\beta-\alpha$ indicates the strength of the habit by determining how much the current habit level restricts future decisions. The smaller the difference $\beta-\alpha$, the stronger the habit.

Remark 1 If $\beta=\alpha$, the habit level would stay constant as long as the agent consumes at the minimum level as can be seen by applying $c(t)=h(t)$ in $(3)$. If $\beta>\alpha$, the habit level would decrease. In either case the constant $r_{A}$ is positive provided that the interest rate is positive. In the case $\beta<\alpha$, the habit level would increase even if the agent consumes at the minimum level, which seems improbable.

Intuitively, the individual splits up her time $t$ wealth into tied-up wealth $h(t) A(t)$ that covers the minimum future consumption and free wealth $X(t)-$ $h(t) A(t)$ that finances excess consumption and thus generates utility. This motivates that the utility maximization problem has a solution of the form presented in the following theorem. See Appendix A for a proof.

\footnotetext{
5 As we want to illustrate in the simplest possible setting that habit formation can induce a consumption habit, we deliberately assume full certainty in our model. If the model would involve uncertainty, $\gamma$ would be a risk aversion parameter. More precisely, the relative risk aversion with respect to consumption gambles would then be $-c \frac{\partial^{2} U(c-h)}{\partial c} / \frac{\partial U(c-h)}{\partial c}=\gamma c /(c-h)$ so that $\gamma$ would be the minimal relative risk aversion possible.
} 
Theorem 1 Assume that the individual at time $t$ has a financial wealth $x$ and a habit level $h$ satisfying $x>h A(t)$, where $A$ is given by (7). Then the indirect utility function is given by

$$
J(t, x, h)=\frac{1}{1-\gamma} g(t)^{\gamma}(x-h A(t))^{1-\gamma},
$$

where

$$
\begin{aligned}
g(t) & =\int_{t}^{T} e^{-r_{g}(s-t)}(1+\alpha A(s))^{\frac{\gamma-1}{\gamma}} d s+\varepsilon^{\frac{1}{\gamma}} e^{-r_{g}(T-t)}, \\
r_{g} & =\frac{\gamma-1}{\gamma} r+\frac{\delta}{\gamma} .
\end{aligned}
$$

The optimal consumption strategy is

$$
c(t)=h(t)+\frac{X(t)-h(t) A(t)}{g(t)}(1+\alpha A(t))^{-\frac{1}{\gamma}} .
$$

Optimal consumption is the sum of the minimum consumption given by the habit level and an age-dependent fraction of the current free wealth. In the following, we are mainly interested in the shape of the function $t \mapsto c(t)$.

Let us briefly consider some special cases. First, consider the case without habit formation which requires $h_{0}=\alpha=\beta=0 .{ }^{6}$ In this case optimal consumption is simply $c(t)=X(t) / g(t)$ and, since $X^{\prime}(t)=\left(r-g(t)^{-1}\right) X(t)$ and $g^{\prime}(t)=r_{g} g(t)-1$, we obtain

$$
c^{\prime}(t)=\frac{\left(r-r_{g}\right) X(t)}{g(t)}=\frac{r-\delta}{\gamma} \frac{X(t)}{g(t)} .
$$

Hence, we see that the consumption function is increasing if $r>\delta$ (the return on savings exceeds the impatience), decreasing if $r<\delta$, and flat if $\delta=r$. Secondly, consider the case where the consumption benchmark $h(t)$ is an exogenously given function (an external habit or a subsistence consumption level) and, in particular, $\alpha=0$ so that consumption does not affect future values of $h(t)$. In this case optimal consumption becomes

$$
c(t)=h(t)+\frac{X(t)-F(t)}{g(t)}, \quad F(t)=\int_{t}^{T} e^{-r(s-t)} h(s) d s,
$$

where $g$ is given by (10) albeit with $\alpha=0$ and we must require $X(t)>F(t)$. Then

$$
c^{\prime}(t)=h^{\prime}(t)+\frac{r-\delta}{\gamma} \frac{X(t)-F(t)}{g(t)},
$$

so $c(t)$ is decreasing if $h(t)$ is decreasing and $\delta>r$, but can be increasing under other assumptions. With a suitably specified benchmark function $h(t)$, the optimal consumption path can even exhibit a hump.

\footnotetext{
6 With uncertainty, this case would correspond to time-additive utility with constant relative risk aversion.
} 
Now we return to the case with (internal) habit formation. Note that direct differentiation with respect to time in (11) would involve the derivatives of both $h(t)$ and $X(t)$, but the latter can be expressed in terms of $X(t)$ and $c(t)$ through (1) and then the $X(t)$ can be expressed in terms of $c(t)$ and $h(t)$ using (11). Hence, the derivative of $c(t)$ can be expressed in terms of $c(t)$ and $h(t)$. From (3), the derivative of $h(t)$ can be expressed in terms of $c(t)$ and $h(t)$. In fact, it turns out to be useful to rewrite the system of derivatives of $c(t)$ and $h(t)$ as a system of derivatives of $c(t)$ and the surplus consumption defined as

$$
\Delta(t)=c(t)-h(t) .
$$

Note that the optimal consumption strategy is such that the surplus consumption is a time-dependent fraction of the free wealth. We summarize the derivatives in the following theorem, which is proved in Appendix B.

Theorem 2 The dynamics of the optimal consumption and the associated surplus consumption is given by the system

$$
\begin{aligned}
d \Delta(t) & =\phi(t) \Delta(t) d t, \\
d c(t) & =(\beta+\phi(t)) \Delta(t) d t-(\beta-\alpha) c(t) d t,
\end{aligned}
$$

where

$$
\begin{aligned}
& \phi(t)=\frac{r-\delta+\alpha B(t)}{\gamma}, \\
& B(t)=\frac{1-r_{A} A(t)}{1+\alpha A(t)}= \begin{cases}\frac{1}{1+\alpha(T-t)}, & \text { if } r_{A}=0, \\
\frac{r_{A}}{\left(r_{A}+\alpha\right) e^{r_{A}(T-t)}-\alpha}, & \text { otherwise. }\end{cases}
\end{aligned}
$$

In the next section we provide analytical results on the existence and location of a hump in the consumption function $t \mapsto c(t)$. Sections 4 and 5 illustrate the results by numerical examples.

\section{Analytical results on the consumption hump}

While the expression (11) for optimal consumption appears simple, it depends on wealth and the habit level, which both are determined by the entire consumption path up to time $t$ via (1) and (2). In general it seems very difficult to analytically establish conditions under which consumption is hump-shaped. For long horizons, however, we can obtain an analytical characterization of the consumption pattern and establish sufficient conditions for the existence of a consumption hump.

Suppose that $\alpha>0$, which means that the habit level is increasing in past consumption, and preferences thus exhibit genuine habit formation. Furthermore, suppose that $r_{A} \geq 0$, where $r_{A}$ is defined in (8). Then it is clear from (18) and (19) that, for any fixed $t, \phi(t)$ smoothly approaches $-\kappa$ as $T \rightarrow \infty$, where

$$
\kappa=\frac{\delta-r}{\gamma} \text {. }
$$


For $T$ large enough, the graph of $\phi(t)$ is almost flat in the early years. We now replace $\phi(t)$ in the true dynamics (16) of the surplus consumption with its limit and thus consider the time-independent dynamics

$$
\begin{aligned}
d \tilde{\Delta}(t) & =-\kappa \tilde{\Delta}(t) d t, \\
d \tilde{c}(t) & =(\beta-\kappa) \tilde{\Delta}(t) d t-(\beta-\alpha) \tilde{c}(t) d t
\end{aligned}
$$

with initial values $\tilde{c}_{0} \geq \tilde{\Delta}_{0}>0$. The following lemma formally shows that we can bound the difference between the true consumption function and its approximation over any interval $[0, t]$ by any margin $\eta>0$ if the planning horizon $T$ is long enough. The proof can be found in Appendix C. In Section 4 we illustrate that, when the model is calibrated to consumption data, the time-independent dynamics (20)-(21) are an accurate approximation of the true dynamics (16)-(17) except possibly for the final years.

Lemma 1 Assume that $\beta+r \geq \alpha>0$. Let the initial values of $\tilde{\Delta}(t)$ and $\tilde{c}(t)$ be given by $\tilde{c}_{0}=c_{0}$ and $\tilde{\Delta}_{0}=c_{0}-h_{0}$. For any given $t \geq 0$ and $\eta>0$, we can then find $\tilde{T}>0$ such that

$$
|c(s)-\tilde{c}(s)|<\eta, \quad s \in[0, t],
$$

whenever $T>\tilde{T}$.

What do we learn about the life-cycle consumption pattern from the timeindependent dynamics? It is instructive first to consider the case $\delta=r$. In the absence of habit formation, optimal consumption is then flat over the life cycle. With habit formation, we have $\kappa=0$ so it follows from (20) that a long-horizon investor optimally holds the consumption-habit difference $\tilde{\Delta}$ constant and thus equal to its initial value $\tilde{\Delta}_{0}=\tilde{c}_{0}-\tilde{h}_{0}$. Since utility depends on the consumption-habit difference, this is the natural counterpart of having constant consumption in the no-habit case. With $\kappa=0$ and $\beta \neq \alpha$, Eqs. (20) and (21) imply that

$$
\tilde{c}(t)=\frac{\beta \tilde{h}_{0}-\alpha \tilde{c}_{0}}{\beta-\alpha} e^{-(\beta-\alpha) t}+\frac{\beta}{\beta-\alpha}\left(\tilde{c}_{0}-\tilde{h}_{0}\right) .
$$

For $\beta>\alpha$, the consumption profile is flat if $\beta \tilde{h}_{0}=\alpha \tilde{c}_{0}$, increasing if $\beta \tilde{h}_{0}<\alpha \tilde{c}_{0}$, and decreasing if $\beta \tilde{h}_{0}>\alpha \tilde{c}_{0}$. The condition for an increasing profile is satisfied if the habit is relatively strong, i.e. $\beta-\alpha$ is small, and the initial habit is relatively small compared to optimal initial consumption.

Next, consider the case $\delta>r$. Without habit formation consumption would be monotonically decreasing over life, but with habit formation the optimal consumption profile can indeed be hump shaped. In this case $\kappa>0$ so that the optimal consumption-habit difference is decreasing over time because of the agent's high degree of impatience. The next theorem establishes a set of sufficient conditions under which the approximating dynamics produce a unique hump in the function $\tilde{c}(t)$. Appendix D provides the proof. 
Theorem 3 Suppose that the conditions

$$
\begin{gathered}
\delta>r \geq 0, \\
\beta-\kappa>\alpha>0, \\
(\alpha-\kappa) \tilde{c}_{0}>(\beta-\kappa) \tilde{h}_{0}
\end{gathered}
$$

hold. Then the solution to the dynamic system (20)-(21) is such that the function $\tilde{c}(t)$ has a unique hump at $t=t_{H}$, where

$$
t_{H}=\frac{\ln (\beta-\alpha)-\ln (\kappa)+\ln \left(1-\frac{\tilde{c}_{0}}{\lambda\left(\tilde{c}_{0}-\tilde{h}_{0}\right)}\right)}{\beta-\alpha-\kappa},
$$

and where

$$
\lambda=\frac{\beta-\kappa}{\beta-\alpha-\kappa} .
$$

The parameter conditions stated in the theorem ensure that the log-terms in (27) are well-defined. When Eq. (24) holds, $\kappa$ is positive, so Eq. (25) sharpens the assumption $\beta+r \geq \alpha$ made in Lemma 1. If we assume $\alpha>\kappa, \tilde{c}_{0}=c_{0}$, and $\tilde{h}_{0}=h_{0}$, the inequality (26) can be rewritten, by applying (11) at $t=0$, as

$$
X_{0}>\left(A(0)+\frac{\beta-\alpha}{\alpha-\kappa} g(0)(1+\alpha A(0))^{1 / \gamma}\right) h_{0}
$$

so that it is satisfied for a large enough initial wealth.

The hump derived from the approximate dynamics occurs at age $t_{H}$. For fixed initial values $\tilde{c}_{0}$ and $\tilde{h}_{0}, t_{H}$ is independent of the horizon $T$. This observation highlights that Theorem 3 is relevant for the hump in the truly optimal consumption path if the horizon is sufficiently large and, in particular, larger than $t_{H}$. We find that $t_{H}$ is increasing in $\tilde{c}_{0}$. Holding $\tilde{c}_{0}$ fixed, $t_{H}$ is increasing in $r, \gamma$, and $\alpha$, but decreasing in $\tilde{h}_{0}, \delta$, and $\beta$.

If the horizon $T$ is long enough, the true dynamics also give rise to a consumption hump as can be seen by an application of Lemma 1 for $t>t_{H}$ and a small $\eta$. For a 40-year horizon and a set of plausible parameters, Section 4 shows that the approximate dynamics are very close to the true dynamics over most of life and that the hump in optimal consumption coincides with the hump in approximate consumption.

\section{Calibrating the model to consumption data}

Our model is designed to produce a closed-form expression for optimal consumption so that the tension between impatience and habit concerns as well as the resulting consumption hump can be studied analytically. To serve that purpose, the model ignores some aspects potentially relevant for the consumption decisions of real-life households. Nevertheless, we show in this section that the consumption pattern in our parsimonious model matches the observed consumption pattern very well. 
We apply consumption data from the Consumer Expenditure Survey from the United States over the period 1980-2003. The data was originally processed and used by Krueger and Perri (2006) and is made available online by the authors. ${ }^{7}$ The consumption is deflated back to represent "1982-84 constant dollars." We apply their so-called ND+ consumption measure; we refer the reader to Krueger and Perri (2006) for details on the data. The consumption data is on a household basis, whereas our model is better suited for individuals. We focus on the consumption of singles and the per-person consumption of couples without children (household consumption divided by 1.7 as recommended by the OECD equivalence scale). The uneven curves in Figure 1 show the average consumption per year in thousands of U.S. dollars for individuals at different ages who are living either as singles (upper panel) or in childless couples (lower panel). The consumption of singles is relatively flat over life, but still higher in mid-life than in the early and in the late years. The consumption of couples exhibits a more pronounced hump-shape. Overall, the consumption profiles are similar to those documented using other (older) data sets by Attanasio and Weber (1995), Attanasio, Banks, Meghir, and Weber (1999), Browning and Crossley (2001), Gourinchas and Parker (2002), and Fernández-Villaverde and Krueger (2007), among others.

We calibrate our model so that the optimal consumption path from the model best matches the observed age-profile of consumption of either singles or couples. Since the consumption data covers ages from 25 to 65 , we let $t=0$ and $T=40$. In the calibration we fix the following parameters. The return on savings is $r=0.02$. The utility weight on bequests is fixed at $\varepsilon=0$, in line with Hurd (1989) who shows empirically that bequest motives are close to zero. The subjective time preference rate is $\delta=0.1$, in accordance with the experimental studies of Andersen et al. (2008) and others. The utility curvature parameter is fixed at $\gamma=4$, which for the case with uncertainty is a reasonable level of relative risk aversion, cf. Meyer and Meyer (2005). The initial wealth is fixed at $X_{0}=370$ (thousand "1982-84 constant dollars" as the consumption data) and represents the sum of a financial wealth and a human capital. In the 2007 Survey of Consumer Finances (SCF), cf., Bucks, Kennickell, Mach, and Moore (2009, A11), the median net worth for families where the age of the head is less than 35 is $\$ 11,800$. Discounting this back to 1984 using a discount rate of $1 \%$, we obtain $\$ 9,386$. To compute an estimate of the human capital we start with an initial 2007 income of $\$ 24,000$, which is consistent with the SCF 2007 median before-tax family income of $\$ 37,400$ for the age group up to 35 years (Bucks et al., A5). The 2007 present value of an income stream for 35 years discounted at $4 \%$ is then $\$ 452,042$, and discounting that back to 1984 at a $1 \%$

7 Web-link: http://www.fperri.net/research_data.htm 


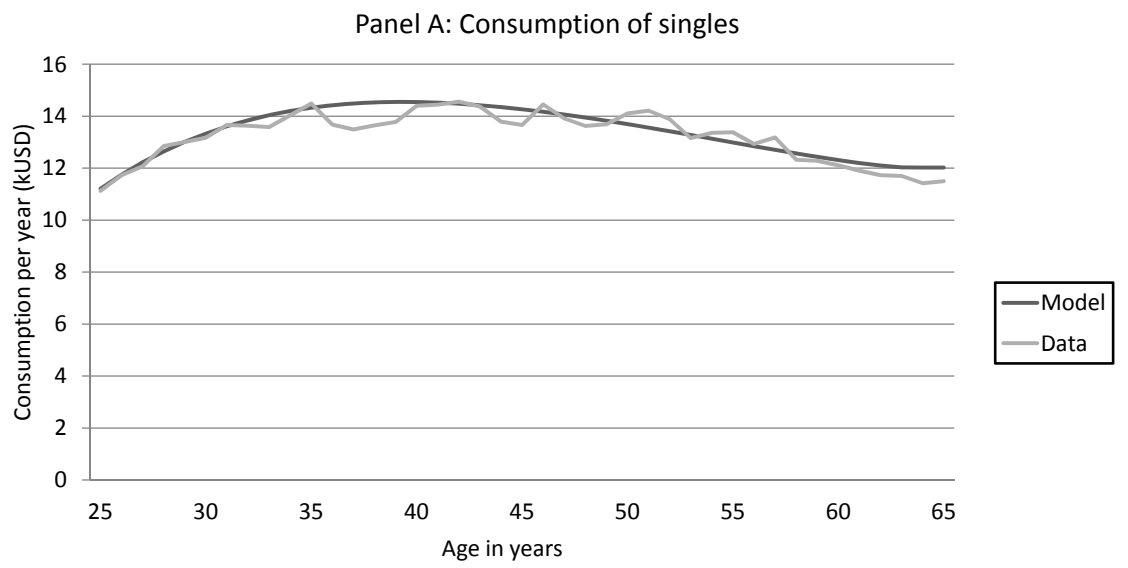

Panel B: Consumption of couples

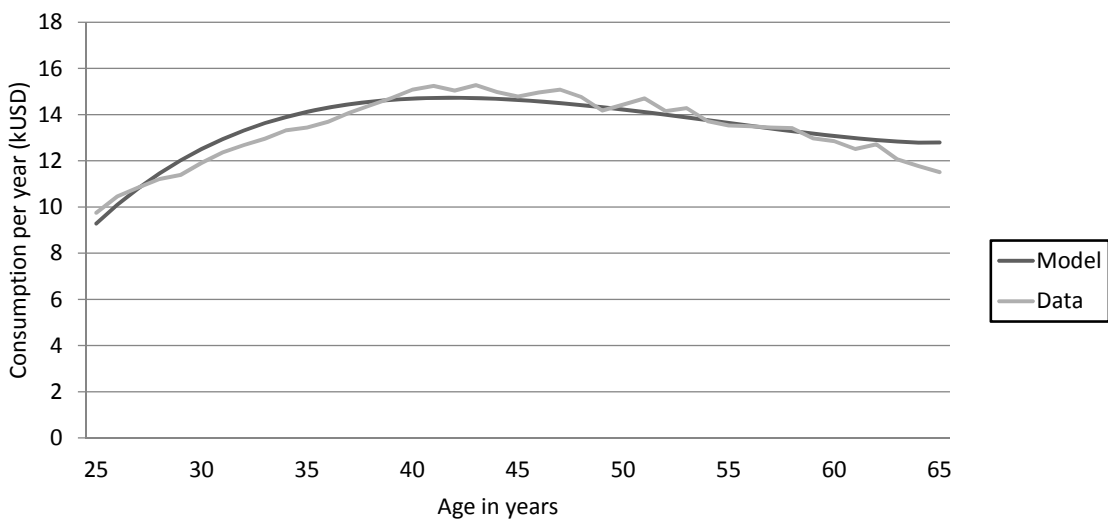

Fig. 1 Consumption path from model calibrated to consumption data. The graphs show annual consumption per person in thousands of dollars deflated to reflect 1982-84 constant dollars. The uneven curve in the upper panel reflects average consumption per year of singles at different ages. The uneven curve in the lower panel shows the average per-person consumption per year of childless couples at different ages. Data is taken from the webpage http://www.fperri.net/research_data.htm of Fabrizio Perri and generated by Krueger and Perri (2006) from the Consumer Expenditure Survey over the period 19802003. The smooth curve in each panel is the consumption pattern in our model calibrated to the data in the way explained in the text.

rate, we get $\$ 359,573 .{ }^{8}$ The sum of the financial and the human wealth would then be $\$ 368.959$, close to the $\$ 370,000$ we use.

8 The $4 \%$ income discount rate can be justified by a risk-free rate of $2 \%$ less an expected income growth rate of $1 \%$ plus a risk premium of $3 \%$ equal to the product of a $10 \%$ income volatility and a market price of risk of 0.3 . An expected income growth rate of $1 \%$ implies that, over a 35-year working period, the income is then expected to grow by a factor $\exp (0.01 \times 35) \approx 1.42$, which seems reasonable and is close to the $38 \%$ reported as the median individual's income growth by Guvenen, Karahan, Ozkan, and Song (2015). An income 


\begin{tabular}{llrr}
\hline \multirow{2}{*}{ Parameter } & Description & \multicolumn{2}{c}{ Consumption data } \\
\cline { 2 - 4 } & & Singles & Couples \\
\hline \multicolumn{2}{c}{ Calibrated values } & & \\
$\alpha$ & habit scaling parameter & 0.100 & 0.117 \\
$\beta$ & habit persistence parameter & 0.174 & 0.181 \\
$h_{0}$ & initial habit level (kUSD) & 2.253 & 0.000 \\
\hline \multicolumn{4}{c}{ Pre-fixed values } \\
$\delta$ & time preference rate & 0.1 & 0.1 \\
$\gamma$ & utility curvature parameter & 4 & 4 \\
$\varepsilon$ & preference weight of bequest & 0 & 0 \\
$X_{0}$ & wealth (kUSD) & 370 & 370 \\
$r$ & risk-free rate & 0.02 & 0.02 \\
$T$ & remaining life time & 40 & 40 \\
\hline
\end{tabular}

Table 1 Parameter values from calibration. The table shows the set of parameter values giving the best fit to the consumption data considered, both for the consumption of singles and the per-person consumption of couples. The data is taken from the webpage http://www.fperri.net/research_data.htm of Fabrizio Perri and generated by Krueger and Perri (2006) from the Consumer Expenditure Survey over the period 1980-2003. The calibration objective is to minimize the sum of the squared differences between the model consumption and the observed average consumption at ages $25,26, \ldots, 65$. We impose the restriction $\alpha \geq 0.1$.

We search for the habit parameters $\alpha, \beta$, and $h_{0}$ with the objective of minimizing the sum of the squared differences between the model consumption and the observed average consumption at ages $25,26, \ldots, 65$. Table 1 shows the parameter values from the calibrations. The habit process parameters $\alpha$ and $\beta$ have very reasonable values. We restrict $\alpha$ to be at least 0.1 , which is a binding constraint in the calibration to the consumption of singles. As long as the difference $\beta-\alpha$ is fixed, we can also obtain an excellent fit to the data for higher values of $\alpha$ and $\beta$. The value of $\beta$ around 0.18 implies that, when computing the current habit, the weight of consumption $n+1$ years ago is roughly $18 \%$ lower than the weight of consumption $n$ years ago, which seems plausible. Both for singles and couples, the difference $\beta-\alpha$ is around 0.07 , implying that the habit declines by $7 \%$ per year as long as the agent consumes at the minimum rate, which also seems reasonable. Direct estimates of the habit parameters $\alpha$ and $\beta$ seem impossible to derive from the existing empirical habit literature, but the values we find are similar those considered by Constantinides (1990) and Munk (2008).

The smooth curves in Figure 1 depict the life-cycle consumption pattern from our calibrated model. The figure illustrates that our parsimonious model nicely matches the observed consumption pattern over the life-cycle including the mid-life consumption hump. The largest difference between our calibrated model and the data occurs for persons of an age between, say, 30 and 45 years who live in a childless couple. However, the observed steep increase in

volatility of $10 \%$ is in line with Cocco, Gomes, and Maenhout (2005) and others. The risk premium also reflects real-life borrowing constraints that lower the present value of future income. 


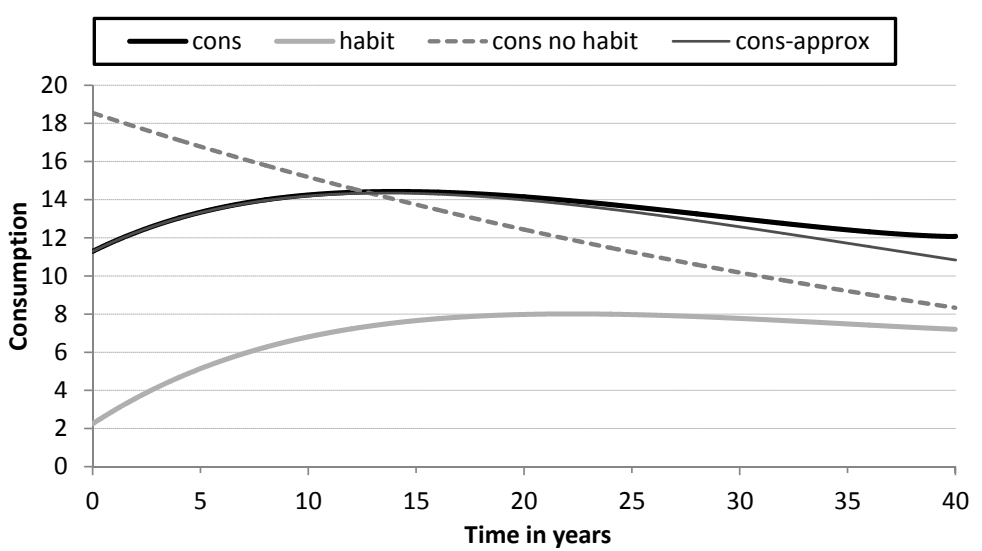

Fig. 2 Consumption in the benchmark case. The black, thick curve shows the optimal consumption path. The pale, thick curve shows the corresponding path of the habit level. The thin solid curve depicts the consumption path based on the approximate, long-horizon dynamics. These curves are generated using the parameters from the calibration of the model to singles' consumption data, cf. Table 1 . The dashed downward-sloping curve shows the optimal consumption path for the case without habit formation; this curve is drawn using the same parameters, except that $h_{0}=\alpha=\beta=0$.

their consumption can be partially explained by a "survivorship bias" in the sample. Obviously, when the persons in a couple become parents, they leave this group of individuals and their subsequent consumption is not reflected by the data we use. If the less wealthy and therefore low-consuming couples are more inclined to become parents, the remaining sample of childless couples is tilted towards the more wealthy and high-consuming individuals.

Based on the parameters from the calibration for singles, Figure 2 shows that the difference between the optimal consumption path (thick black curve) and the habit level (solid grey curve) is decreasing over life which, as explained earlier, occurs because the time preference rate $\delta$ exceeds the rate of return $r$ on savings. The dashed curve represents the optimal consumption path of an agent not developing habits, which is monotonically decreasing since $\delta>r$. Habit formation thus has a dramatic effect on the optimal consumption path. Finally, the thin solid curve depicts the consumption path based on the approximate, long-horizon dynamics defined by Eqs. (20) and (21). Over the first 20 years the approximate consumption path is indistinguishable from the optimal path, and the difference between the two curves remains small throughout life.

\section{Parameter sensitivity}

In this section we investigate the sensitivity of the consumption path and the location of the consumption hump with respect to the values of key parameters. 


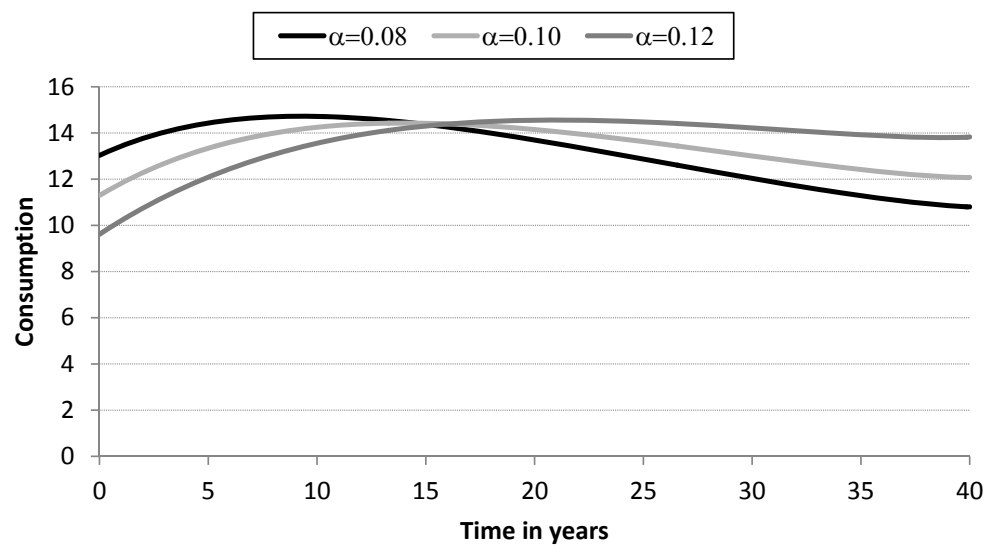

Fig. 3 Consumption for different values of the habit scaling parameter $\alpha$. For all other parameters the values from the calibration to singles' consumption data are used, cf. Table 1.

We vary parameter values around a benchmark which we take to be the values obtained in the calibration to the consumption data for singles, cf. Table 1.

Figure 3 shows the optimal consumption profile for three different values of the habit scaling parameter $\alpha$. Increasing $\alpha$, current consumption has a bigger effect on future habit levels, which leads the agent to lower consumption in the early years. The increased savings are spent on higher consumption in the late years of life. Consequently, the consumption hump occurs later in life. For very small values of $\alpha$ (in our case around 0.041 and smaller), the consumption profile is monotonically decreasing over life, as in the case without habits, since then the habit level does not have a sufficient magnitude to subdue the impatience of the agent. Conversely, for very high values of $\alpha$ (in our case around 0.135 and higher), the consumption profile is monotonically increasing.

Figure 4 illustrates the importance of the habit persistence parameter $\beta$. A higher $\beta$ reduces the influence of current consumption on future habit levels. Hence, the agent initially consumes more, which is naturally offset by lower consumption late in life. A higher $\beta$ therefore also leads to an earlier consumption hump. If $\beta$ is sufficiently high (around 0.657 and higher in our case), the hump disappears and consumption monotonically decreases over life except for the few final years where consumption increases. If $\beta$ is sufficiently small ( 0.136 or lower), the optimal consumption is monotonically increasing over life.

The role of the time preference rate $\delta$ can be seen in Figure 5. A higher $\delta$ means that the agent is more impatient and therefore increases consumption early in life with the consequence of reducing consumption late in life, which causes the consumption hump to occur earlier in life. Because a high early consumption raises the minimum consumption level in the following years, it takes a high value of $\delta$ (in our case 0.388 or higher) before the consumption 


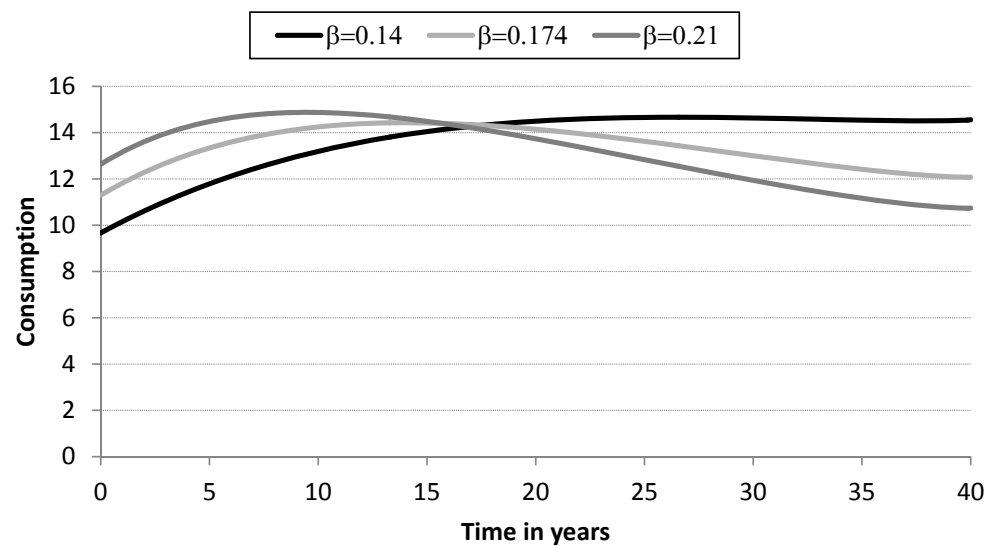

Fig. 4 Consumption for different values of the habit persistence parameter $\beta$. For all other parameters the values from the calibration to singles' consumption data are used, cf. Table 1.

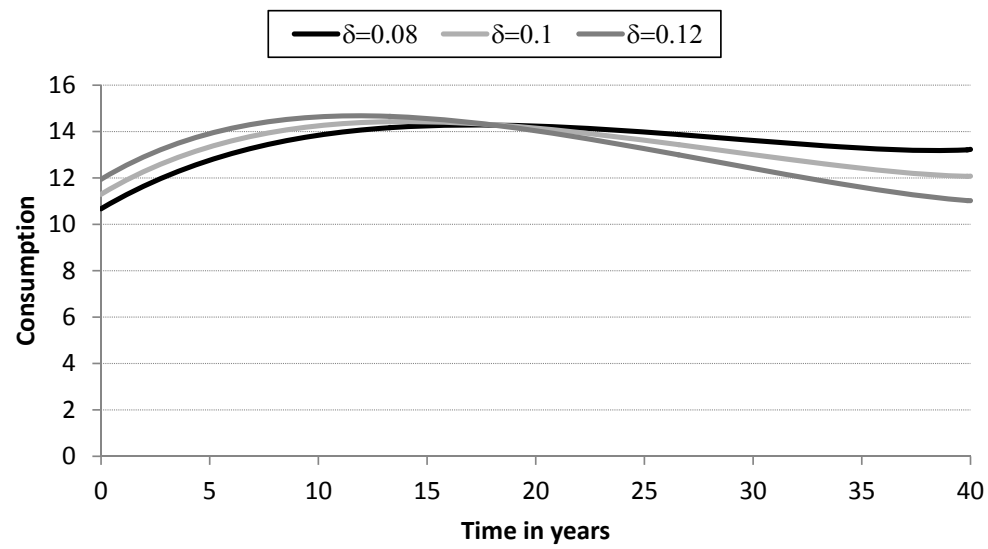

Fig. 5 Consumption for different values of the time preference rate $\delta$. For all other parameters the values from the calibration to singles' consumption data are used, cf. Table 1.

path becomes downward-sloping right from the beginning. For low values of $\delta$ (around 0.054 and lower), the optimal consumption profile is monotonically increasing. Note that this happens also for cases in which optimal consumption without habit formation is monotonically decreasing; in our case this occurs for $\delta$ between 0.02 (the benchmark value of $r$ ) and 0.054 .

Figure 6 shows that a higher value of the utility curvature parameter $\gamma$ leads to lower consumption early in life and higher consumption late in life with the consumption hump occurring later in life. For high values of $\gamma$ (around 


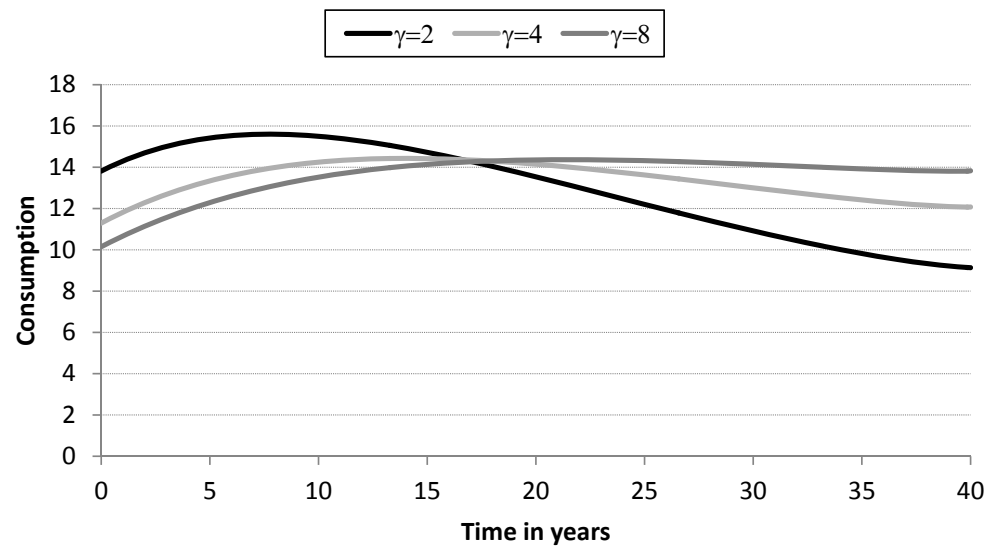

Fig. 6 Consumption for different values of the utility curvature parameter $\gamma$. For all other parameters the values from the calibration to singles' consumption data are used, cf. Table 1.

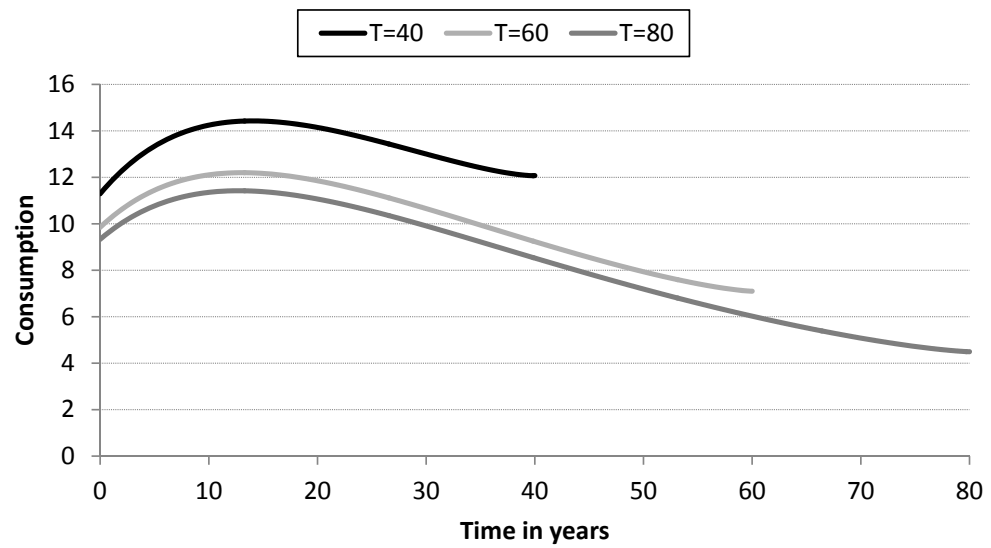

Fig. 7 Consumption for different values of the time horizon $T$. For all other parameters the values from the calibration to singles' consumption data are used, cf. Table 1.

17.3 or higher), consumption is monotonically increasing. For low values of $\gamma$ (around 0.86 or lower), consumption is decreasing.

Figure 7 illustrates the optimal consumption profile for three different values of the time horizon $T$. Since we fix the initial wealth, the agent with a longer horizon consumes at a lower level throughout life. The consumption hump occurs earlier for longer horizons. For a sufficiently short horizon (about 25.3 years or shorter, given the other parameter values) the consumption path is monotonically increasing over life.

Next, we consider the relevance of the strength of the bequest motive as represented by the parameter $\varepsilon$, cf. the preference specification in (4). We 


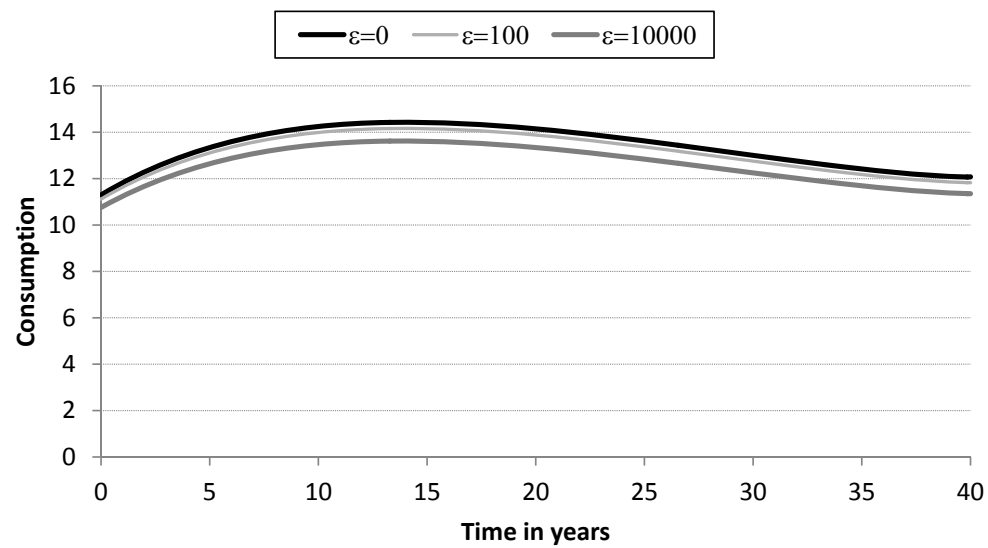

Fig. 8 Consumption for different values of the bequest parameter $\varepsilon$. For all other parameters the values from the calibration to singles' consumption data are used, cf. Table 1.

have used a benchmark value of $\varepsilon=0$, which obviously implies that the agent consumes everything and ends up with zero wealth. In Figure 8 we compare the benchmark consumption profile with the consumption profile when $\varepsilon$ is either 100 or 10,000 . In the first of these two cases, the agent leaves a bequest of 15.1 (compare with the initial wealth of 370) which corresponds to roughly the consumption in the final 1.3 years. In the latter case, the agent leaves a bequest of 45.6 roughly corresponding to the consumption over the final 4 years. Naturally, we see that the stronger the bequest weight $\varepsilon$, the lower the consumption throughout life as more savings need to be generated. However, the shape of the consumption profile and the location of the consumption hump are only affected slightly. The hump occurs after 14.04 years without bequest, after 13.98 years when $\varepsilon=100$, and after 13.86 years when $\varepsilon=10,000$.

Finally, Figure 9 illustrates how the consumption profile varies with the initial habit level $h_{0}$. A higher initial habit induces a higher initial consumption at the expense of lower consumption later in life, so the consumption hump occurs earlier. In fact, when the initial habit is sufficiently high, the consumption path becomes monotonically decreasing over life as shown by the curve for $h_{0}=8$. In all cases, the consumption-habit difference is decreasing over life because the agent's time preference rate exceeds the rate of return on savings.

\section{Robustness}

The model we have considered above assumes (i) a power utility function of the difference between the consumption rate and the habit level, cf. Eqs. (4)-(5), and (ii) the linear habit dynamics given by Eqs. (2)-(3). Both assumptions are crucial to obtain a closed-form solution. However, the underlying intuition 


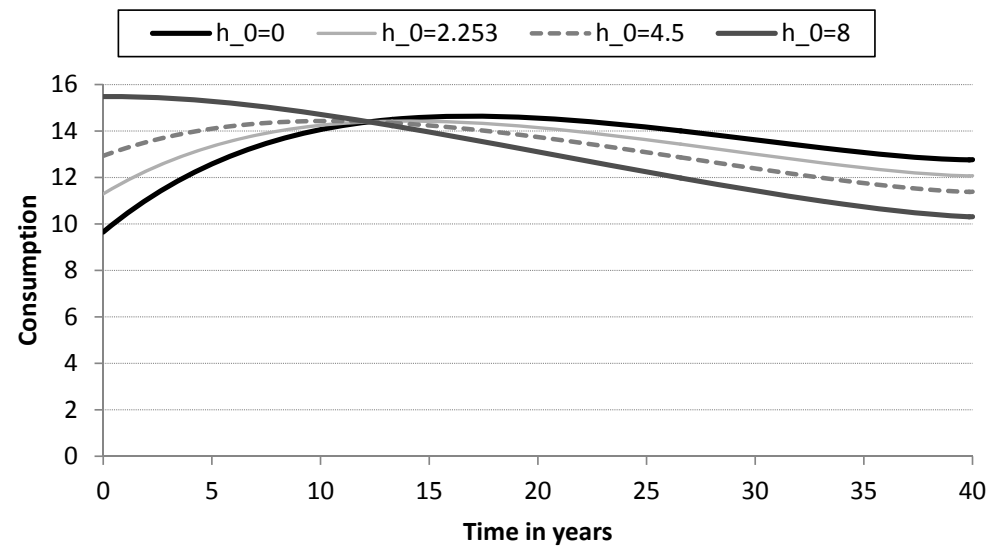

Fig. 9 Consumption for different values of the initial habit level $h_{0}$. For all other parameters the values from the calibration to singles' consumption data are used, cf. Table 1.

suggests that other specifications of the habit can also lead to a consumption hump.

We consider an alternative utility specification in which the habit level enters the utility function multiplicatively,

$$
U\left(c(s) h(s)^{-\psi}\right)=\frac{1}{1-\gamma}\left(\frac{c(s)}{h(s)^{\psi}}\right)^{1-\gamma}
$$

where $\psi \geq 0$ to ensure that marginal utility of consumption is increasing in the habit level when $\gamma>1$ as is typically assumed. This utility specification has been used by Abel (1990, 1999), Carroll, Overland, and Weil (2000), Fuhrer (2000), and Amato and Laubach (2004), among others.

We also consider the log-additive habit dynamics

$$
d \ln h(t)=[\alpha \ln (c(t))-\beta \ln (h(t))] d t,
$$

which has the closed-form solution

$$
h(t)=h(0) \exp \left\{\alpha \int_{0}^{t} e^{-\beta(t-s)} \ln (c(s)) d s\right\} .
$$

This is the continuous-time analogue of the discrete-time habit dynamics studied by Kozicki and Tinsley (2002, Eq. 19) and Corrado and Holly (2011, Eqs. 4-5). Furthermore, the famous Campbell and Cochrane (1999) asset pricing model has very similar habit dynamics as explained by Campbell, Lo, and MacKinlay (1997, p. 331).

More precisely, we study three alternative model specifications:

Alternative 1: The multiplicative utility (30) and the original additive habit dynamics (3). 


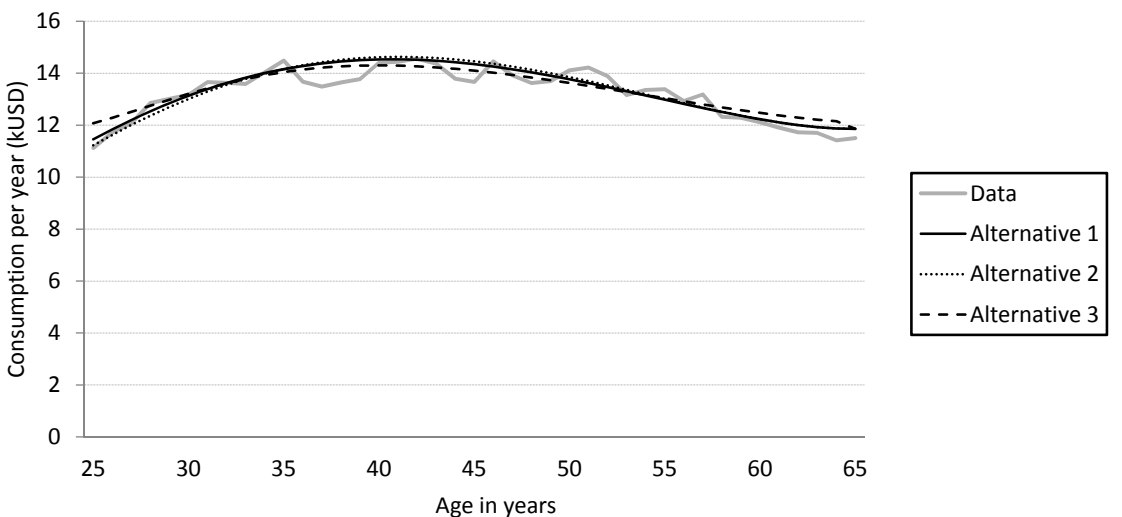

Fig. 10 Calibration of alternative models to consumption data. The graphs show annual consumption per person in thousands of dollars deflated to reflect 1982-84 constant dollars. The uneven curve reflects average consumption per year of singles at different ages. Data is taken from the webpage http://www.fperri.net/research_data.htm of Fabrizio Perri and generated by Krueger and Perri (2006) from the Consumer Expenditure Survey over the period 1980-2003. The smooth curves are the consumption patterns in the three alternative models explained in the text.

Alternative 2: The original additive utility $U(c-h)$ with $U$ given by (5) and the log-additive habit dynamics (31).

Alternative 3: The multiplicative utility (30) and the log-additive habit dynamics (31).

In all cases we determine optimal consumption by numerically solving the Hamilton-Jacobi-Bellman equation and find that the consumption profile can be hump shaped. In fact, Figure 10 shows that the alternative models also provide a good fit to the hump-shaped consumption pattern in the data. For brevity, we only show the calibration to the consumption of singles, but the results are similar for the consumption of couples. As in the calibration of our main model in Section 4, we fix the values of $\delta, \gamma, \varepsilon, X_{0}, r$, and $T$ as shown in Table 1 . When applying the multiplicative utility (30), we fix $\psi=1$. We then vary $\alpha, \beta$, and $h_{0}$ to obtain the best fit to the data, which leads to the parameter values listed in Table 2 .

\section{Conclusion}

This paper proposes a new potential explanation of the empirically observed hump in the consumption of individuals over their life cycle. If the preferences of the individual exhibit habit formation, the hump can naturally materialize from a tradeoff between impatience and concerns about the effects of current 


\begin{tabular}{llccc}
\hline Parameter & Description & Alt. 1 & Alt. 2 & Alt. 3 \\
\hline$\alpha$ & habit scaling parameter & 0.100 & 0.137 & 0.100 \\
$\beta$ & habit persistence parameter & 0.110 & 0.175 & 0.110 \\
$h_{0}$ & initial habit level (kUSD) & 6.988 & 2.079 & 5.061 \\
\hline
\end{tabular}

Table 2 Parameter values from calibration of alternative models. The table shows the set of parameter values giving the best fit to the consumption data for singles. The data is taken from the webpage http://www.fperri.net/research_data.htm of Fabrizio Perri and generated by Krueger and Perri (2006) from the Consumer Expenditure Survey over the period 1980-2003. The calibration objective is to minimize the sum of the squared differences between the consumption in the model with multiplicative habit utility and the observed average consumption at ages $25,26, \ldots, 65$. We impose the restriction $\alpha \geq 0.1$. Parameters not listed are fixed at the values stated in Table 1.

consumption on future habit levels and thus future minimum consumption. The habit concerns cause a large reduction in the otherwise very high consumption early in life, but a smaller reduction of the otherwise medium-sized consumption in mid life. In some circumstances, a hump-shaped consumption path emerges.

We present a set of sufficient conditions for the presence of a hump and characterize the age at which the hump occurs. We show that our parsimonious model closely matches the consumption patterns derived from the 1980-2003 U.S. Consumer Expenditure Surveys. Numerical examples illustrate the sensitivity of the optimal consumption path and the location of the hump to the values of key model parameters. We show that our main findings are robust to the exact specification of how the habit level enters the utility function and how the habit level is determined from past consumption.

As the purpose of the paper is to demonstrate that habit formation can generate a consumption hump, we deliberately keep our model simple and, in particular, disregard uncertainty, labor income, portfolio constraints etc. However, the basic tradeoff identified in this paper carries over to more elaborate settings.

\section{A Proof of Theorem 1}

The Hamilton-Jacobi-Bellman (HJB) equation associated with the utility maximization problem (6) is

$$
0=\max _{c}\left\{\frac{1}{1-\gamma}(c-h)^{1-\gamma}+J_{t}+r x J_{x}-c J_{x}-\delta J+(\alpha c-\beta h) J_{h}\right\},
$$

where we have suppressed the arguments of the functions and where subscripts on $J$ indicate partial derivatives. The terminal condition is

$$
J(T, x, h)=\varepsilon U(x)=\frac{\varepsilon}{1-\gamma} x^{1-\gamma} .
$$

The first-order condition is

$$
-J_{x}+(c-h)^{-\gamma}+\alpha J_{h}=0 \quad \Leftrightarrow \quad c=h+\left(J_{x}-\alpha J_{h}\right)^{-\frac{1}{\gamma}} .
$$


The second-order condition is satisfied by concavity of the utility function. After substituting the first-order condition back into the HJB equation and simplifying, we see that $J$ should satisfy the partial differential equation (PDE)

$$
0=\frac{\gamma}{1-\gamma}\left(J_{x}-\alpha J_{h}\right)^{1-\frac{1}{\gamma}}+J_{t}+r x J_{x}-h J_{x}-\delta J+(\alpha-\beta) h J_{h}
$$

We conjecture that

$$
J(t, x, h)=\frac{1}{1-\gamma} g(t)^{\gamma}(x-h A(t))^{1-\gamma}
$$

for some deterministic functions $g$ and $A$. The relevant derivatives are

$$
\begin{gathered}
J_{t}=-A_{t} h(x-h A)^{-\gamma} g^{\gamma}+\frac{\gamma}{1-\gamma}(x-h A)^{1-\gamma} g^{\gamma-1} g_{t}, \\
J_{x}=(x-h A)^{-\gamma} g^{\gamma}, \quad J_{h}=-A(x-h A)^{-\gamma} g^{\gamma} .
\end{gathered}
$$

By substituting the derivatives into the first-order condition (34), we obtain

$$
c=h+\left((x-h A)^{-\gamma} g^{\gamma}+\alpha A(x-h A)^{-\gamma} g^{\gamma}\right)^{-1 / \gamma}=h+\frac{x-h A}{g}(1+\alpha A)^{-1 / \gamma} .
$$

After substitution of the derivatives, the PDE (35) can be written as

$$
\begin{aligned}
0= & h g^{\gamma}(x-h A)^{-\gamma}\left[-A_{t}+(r+\beta-\alpha) A-1\right] \\
& +\frac{\gamma}{1-\gamma} g^{\gamma-1}(x-h A)^{1-\gamma}\left[g_{t}-\frac{1}{\gamma}(\delta+(\gamma-1) r) g+(1+\alpha A)^{1-\frac{1}{\gamma}}\right]
\end{aligned}
$$

which is satisfied if $A$ and $g$ satisfy the ordinary differential equations (ODEs)

$$
A_{t}=(r+\beta-\alpha) A-1, \quad g_{t}=\frac{1}{\gamma}(\delta+(\gamma-1) r) g-(1+\alpha A)^{1-\frac{1}{\gamma}} .
$$

Because of the terminal condition (33), we also need $A(T)=0$ and $g(T)=$ $\varepsilon^{1 / \gamma}$. It is straightforward to verify that these conditions and the above ODEs are indeed satisfied when the functions $A$ and $g$ are given by (7) and (10), respectively.

\section{B Proof of Theorem 2}

From (11), we can write

$$
\Delta(t)=(X(t)-h(t) A(t)) H(t), \quad H(t)=\frac{(1+\alpha A(t))^{-\frac{1}{\gamma}}}{g(t)} .
$$


Straightforward differentiation leads to

$$
\begin{aligned}
\Delta^{\prime}(t)= & \left(X^{\prime}(t)-h^{\prime}(t) A(t)-h(t) A^{\prime}(t)\right) H(t)+(X(t)-h(t) A(t)) H^{\prime}(t) \\
= & \left(r X(t)-c(t)-[\alpha c(t)-\beta h(t)] A(t)-h(t)\left[r_{A} A(t)-1\right]\right) H(t) \\
& \quad+\Delta(t) \frac{H^{\prime}(t)}{H(t)} \\
= & (r X(t)-c(t)-\alpha c(t) A(t)-h(t)[(r-\alpha) A(t)-1]) H(t)+\Delta(t) \frac{H^{\prime}(t)}{H(t)} \\
= & r(X(t)-h(t) A(t)) H(t)-(c(t)-h(t))(1+\alpha A(t)) H(t)+\Delta(t) \frac{H^{\prime}(t)}{H(t)} \\
= & \Delta(t)\left(r-(1+\alpha A(t)) H(t)+\frac{H^{\prime}(t)}{H(t)}\right),
\end{aligned}
$$

where we have used $X^{\prime}(t)=r X(t)-c(t)$ and $h^{\prime}(t)=\alpha c(t)-\beta h(t)$, as well as $A^{\prime}(t)=r_{A} A(t)-1$. By further applying that $g^{\prime}(t)=r_{g} g(t)-(1+\alpha A(t))^{1-\frac{1}{\gamma}}$, we obtain

$$
\begin{aligned}
H^{\prime}(t)=- & \frac{\alpha}{\gamma} \frac{(1+\alpha A(t))^{-\frac{1}{\gamma}-1} A^{\prime}(t)}{g(t)}-(1+\alpha A(t))^{-\frac{1}{\gamma}} \frac{g^{\prime}(t)}{g(t)^{2}} \\
=- & \frac{\alpha}{\gamma} \frac{r_{A} A(t)-1}{1+\alpha A(t)} H(t)-r_{g} \frac{(1+\alpha A(t))^{-\frac{1}{\gamma}}}{g(t)} \\
& +(1+\alpha A(t))\left(\frac{(1+\alpha A(t))^{-\frac{1}{\gamma}}}{g(t)}\right)^{2} \\
= & \frac{\alpha}{\gamma} B(t) H(t)-r_{g} H(t)+(1+\alpha A(t)) H(t)^{2}
\end{aligned}
$$

where we have introduced

$$
B(t)=\frac{1-r_{A} A(t)}{1+\alpha A(t)} .
$$

Going back to the derivative of the surplus consumption, we get

$$
\begin{aligned}
\Delta^{\prime}(t) & =\Delta(t)\left(r-(1+\alpha A(t)) H(t)+\frac{\alpha}{\gamma} B(t)-r_{g}+(1+\alpha A(t)) H(t)\right) \\
& =\Delta(t)\left(r-r_{g}+\frac{\alpha}{\gamma} B(t)\right) \\
& =\Delta(t) \frac{1}{\gamma}(r-\delta+\alpha B(t)) \\
& =\Delta(t) \phi(t)
\end{aligned}
$$

where

$$
\phi(t)=\frac{r-\delta+\alpha B(t)}{\gamma}
$$


Since $c(t)=h(t)+\Delta(t)$ by definition, we obtain

$$
\begin{aligned}
c^{\prime}(t) & =h^{\prime}(t)+\Delta^{\prime}(t) \\
& =(\alpha c(t)-\beta h(t))+\Delta(t) \phi(t) \\
& =(\beta+\phi(t)) \Delta(t)+(\alpha-\beta) c(t),
\end{aligned}
$$

which completes the proof.

\section{Proof of Lemma 1}

Define $f(s)=c(s)-\tilde{c}(s)$ and note that $f(0)=0$. From (17) and (21), we get

$$
\begin{aligned}
d f(s) & =[(\beta+\phi(s)) \Delta(s)-(\beta-\kappa) \tilde{\Delta}(s)] d s+[(\alpha-\beta) c(s)-(\alpha-\beta) \tilde{c}(s)] d s \\
& =[(\beta+\phi(s))(\Delta(s)-\tilde{\Delta}(s))+(\phi(s)+\kappa) \tilde{\Delta}(s)] d s+(\alpha-\beta) f(s) d s .
\end{aligned}
$$

Noting that $\tilde{\Delta}(s)=\tilde{\Delta}_{0} e^{-\kappa s}$, we can write the solution as

$$
\begin{aligned}
f(s) & =\int_{0}^{s} e^{-(\beta-\alpha)(s-\tau)}[(\beta+\phi(\tau))(\Delta(\tau)-\tilde{\Delta}(\tau))+(\phi(\tau)+\kappa) \tilde{\Delta}(\tau)] d \tau \\
& =\tilde{\Delta}_{0} \int_{0}^{s} e^{-(\beta-\alpha)(s-\tau)} e^{-\kappa \tau}\left[(\beta+\phi(\tau))\left(\frac{\Delta(\tau)}{\tilde{\Delta}(\tau)}-1\right)+(\phi(\tau)+\kappa)\right] d \tau .
\end{aligned}
$$

By (18), (19), and the assumption $\alpha>0$, the function $\beta+\phi(\tau)$ is uniformly bounded for $\tau \in[0, t]$ by a constant $K>0$ which is independent of $T$. Obviously, this also holds for the functions $e^{-(\beta-\alpha)(s-\tau)}$ and $e^{-\kappa \tau}$. Furthermore,

$$
\frac{\Delta(\tau)}{\tilde{\Delta}(\tau)}=\frac{\Delta_{0} e^{\int_{0}^{\tau} \phi(u) d u}}{\tilde{\Delta}_{0} e^{-\kappa \tau}}=e^{\int_{0}^{\tau}(\phi(u)+\kappa) d u},
$$

where we apply $\tilde{\Delta}_{0}=\Delta_{0}$ which follows from assuming $\tilde{h}_{0}=h_{0}$ and $\tilde{c}_{0}=c_{0}$. For any $\nu>0$ we can find a $\tilde{T}>0$ big enough that $|\phi(u)+\kappa|<\nu$ for all $u \in[0, t]$ if $T>\tilde{T}$. It follows that

$$
|f(s)| \leq \tilde{\Delta}_{0} \int_{0}^{s}\left[K\left(e^{\nu s}-1\right)+\nu\right] d \tau \leq t \tilde{\Delta}_{0}\left[K\left(e^{\nu t}-1\right)+\nu\right], \quad s \in[0, t] .
$$

If we decrease $\nu$ from positive values towards zero, the right-hand side in this inequality decreases towards zero. Hence, for any given $\eta>0$, we can find a small enough $\nu>0$ and therefore a corresponding large enough $\tilde{T}$ so that, for $T>\tilde{T}$

$$
|f(s)|<\eta, \quad s \in[0, t] .
$$




\section{Proof of Theorem 3}

Note that when the conditions (24)-(25) hold, we have $\kappa>0, \beta>\alpha$, and $\lambda>1$.

The solutions to $(20)-(21)$ are

$$
\begin{aligned}
\tilde{\Delta}(t) & =\tilde{\Delta}_{0} e^{-\kappa t} \\
\tilde{c}(t) & =\left(\tilde{c}_{0}-\lambda \tilde{\Delta}_{0}\right) e^{-(\beta-\alpha) t}+\lambda \tilde{\Delta}_{0} e^{-\kappa t}
\end{aligned}
$$

as can be verified by straightforward differentiation. Observe that

$$
\tilde{c}^{\prime}(0)=(\beta-\kappa) \tilde{\Delta}_{0}+(\alpha-\beta) \tilde{c}_{0}=(\alpha-\kappa) \tilde{c}_{0}-(\beta-\kappa) \tilde{h}_{0},
$$

which is positive because of the condition (26). On the other hand, we can write

$$
\tilde{c}^{\prime}(t)=e^{-\kappa t}\left((\beta-\alpha)\left(\lambda \tilde{\Delta}_{0}-\tilde{c}_{0}\right) e^{-(\beta-\alpha-\kappa) t}-\kappa \lambda \tilde{\Delta}_{0}\right) .
$$

Because of the conditions (24)-(25), the first term in the brackets approaches zero as $t \rightarrow \infty$ and the second term $\kappa \lambda \tilde{\Delta}_{0}$ is positive. Therefore, $\tilde{c}^{\prime}(t)<0$ for large enough $t$.

Because $\tilde{c}^{\prime}(t)$ is a smooth function with $\tilde{c}^{\prime}(0)>0$ and $\tilde{c}^{\prime}(t)<0$ for large enough $t$, there must be at least one point $t_{H}$ for which $\tilde{c}^{\prime}\left(t_{H}\right)=0$. The condition $\tilde{c}^{\prime}\left(t_{H}\right)=0$ implies that

$$
(\beta-\alpha)\left(\lambda \tilde{\Delta}_{0}-\tilde{c}_{0}\right) e^{-(\beta-\alpha-\kappa) t_{H}}=\kappa \lambda \tilde{\Delta}_{0}
$$

where both sides of the equality are positive due to the parameter conditions. Hence, the solution is

$$
\begin{aligned}
t_{H} & =\frac{1}{\beta-\alpha-\kappa} \ln \left(\frac{(\beta-\alpha)\left(\lambda \tilde{\Delta}_{0}-\tilde{c}_{0}\right)}{\kappa \lambda \tilde{\Delta}_{0}}\right) \\
& =\frac{\ln (\beta-\alpha)-\ln (\kappa)+\ln \left(1-\frac{\tilde{c}_{0}}{\lambda\left(\tilde{c}_{0}-\tilde{h}_{0}\right)}\right)}{\beta-\alpha-\kappa} .
\end{aligned}
$$

This is the only solution to $\tilde{c}^{\prime}\left(t_{H}\right)=0$ since the term in the brackets in (38) is a decreasing function of $t$. Combining this with the above observation that $\tilde{c}^{\prime}(t)<0$ for large enough $t$, it becomes clear that $\tilde{c}(t)$ is hump-shaped, i.e., increasing from $t=0$ up to $t=t_{H}$ where it attains its maximum and then decreasing for $t>t_{H}$.

\section{References}

Abel, A. B. (1990). Asset Prices under Habit Formation and Catching up with the Joneses. Am Econ Rev 80(2), 38-42.

Abel, A. B. (1999). Risk Premia and Term Premia in General Equilibrium. J Monetary Econ 43(1), 3-33. 
Amato, J. D. and T. Laubach (2004). Implications of Habit Formation for Optimal Monetary Policy. J Monetary Econ 51(2), 305-325.

Andersen, S., G. W. Harrison, M. I. Lau, and E. E. Rutström (2008). Eliciting Risk and Time Preferences. Econometrica 76(3), 583-618.

Attanasio, O. P., J. Banks, C. Meghir, and G. Weber (1999). Humps and Bumps in Lifetime Consumption. J Bus Econ Stat 17(1), 22-35.

Attanasio, O. P. and M. Browning (1995). Consumption over the Life Cycle and over the Business Cycle. Am Econ Rev 85(5), 1118-1137.

Attanasio, O. P. and G. Weber (1995). Is Consumption Growth Consistent with Intertemporal Optimization? Evidence from the Consumer Expenditure Survey. J Polit Econ 103(6), 1121-1157.

Becker, G. S. (1965). A Theory of the Allocation of Time. Econ J 75(299), 493-517.

Betermier, S., L. E. Calvet, and P. Sodini (2015). Who are the Value and Growth Investors? Available at SSRN: http://ssrn.com/abstract= 2426823.

Boldrin, M., L. J. Christiano, and J. D. M. Fisher (2001). Habit Persistence, Asset Returns, and the Business Cycle. Am Econ Rev 91(1), 149-166.

Browning, M. (1991). A Simple Nonadditive Preference Structure for Models of Household Behavior over Time. J Polit Econ 99(3), 607-637.

Browning, M. and M. D. Collado (2007). Habits and Heterogeneity in Demands: A Panel Data Analysis. J Appl Econom 22(3), 625-640.

Browning, M. and T. Crossley (2001). The Life-Cycle Model of Consumption and Saving. J Econ Perspect 15(3), 3-22.

Browning, M. and M. Ejrnæs (2009). Consumption and Children. Rev Econ Stat 91(1), 93-111.

Bucks, B. K., A. B. Kennickell, T. L. Mach, and K. B. Moore (2009). Changes in U.S. Family Finances from 2004 to 2007: Evidence from the Survey of Consumer Finances. Federal Reserve Bulletin, February.

Campbell, J. Y. and J. H. Cochrane (1999). By Force of Habit: A Consumption-Based Explanation of Aggregate Stock Market Behavior. $J$ Polit Econ 107(2), 205-251.

Campbell, J. Y., A. W. Lo, and A. C. MacKinlay (1997). The Econometrics of Financial Markets. Princeton University Press.

Carrasco, R., J. M. Labeaga, and J. D. Lopez-Salido (2005). Consumption and Habits: Evidence from Panel Data. Econ J 115(500), 144-165.

Carroll, C. D. (1997). Buffer-Stock Saving and the Life Cycle/Permanent Income Hypothesis. Q J Econ 112(1), 1-55.

Carroll, C. D., J. Overland, and D. N. Weil (2000). Saving and Growth with Habit Formation. Am Econ Rev 90(3), 341-355.

Chen, X. and S. C. Ludvigson (2009). Land of Addicts? An Empirical Investigation of Habit-Based Asset Pricing Models. J Appl Econom 24(7), 1057-1093.

Christiano, L., M. Eichenbaum, and C. Evans (2005). Nominal Rigidities and the Dynamic Effects of a Shock to Monetary Policy. J Polit Econ 113(1), 1-45. 
Cocco, J. F., F. J. Gomes, and P. J. Maenhout (2005). Consumption and Portfolio Choice over the Life Cycle. Rev Financ Stud 18(2), 491-533.

Constantinides, G. M. (1990). Habit Formation: A Resolution of the Equity Premium Puzzle. J Polit Econ 98(3), 519-543.

Corrado, L. and S. Holly (2011). Multiplicative Habit Formation and Consumption: A Note. Econ Lett 113(2), 116-119.

Del Negro, M., F. Schorfheide, F. Smets, and R. Wouters (2007). On the Fit of New Keynesian Models. J Bus Econ Stat 25(2), 123-162.

Diaz, A., J. Pijoan-Mas, and J.-V. Rios-Rull (2003). Precautionary Savings and Wealth Distribution under Habit Formation Preferences. J Monetary Econ 50(6), 1257-1291.

Domeij, D. and M. Johannesson (2006). Consumption and Health. BE J Macroecon (Contributions) 6(1), 1-30.

Feigenbaum, J. (2008). Can Mortality Risk Explain the Consumption Hump? J Macroecon 30(3), 844-872.

Fernández-Villaverde, J. and D. Krueger (2007). Consumption over the Life Cycle: Facts from Consumer Expenditure Survey Data. Rev Econ Stat 89(3), 552-565.

Fernández-Villaverde, J. and D. Krueger (2011). Consumption and Saving over the Life Cycle: How Important are Consumer Durables? Macroecon Dyn 15(5), 725-770.

Fisher, I. (1930). The Theory of Interest. Macmillan.

Friedman, M. (1957). A Theory of the Consumption Function. Princeton University Press for NBER.

Fuhrer, J. C. (2000). Habit Formation in Consumption and Its Implications for Monetary-Policy Models. Am Econ Rev 90(3), 367-390.

Gourinchas, P.-O. and J. A. Parker (2002). Consumption Over the Life Cycle. Econometrica 70(1), 47-89.

Grischenko, O. V. (2010). Internal vs. External Habit Formation: The Relative Importance for Asset Pricing. J Econ Bus 62(3), 176-194.

Guvenen, F., F. Karahan, S. Ozkan, and J. Song (2015, February). What Do Data on Millions of U.S. Workers Reveal About Life-Cycle Earnings Risk. Available at SSRN: http://ssrn. com/abstract=2563279.

Hansen, G. D. and S. Imrohoroğlu (2008). Consumption over the Life Cycle: The Role of Annuities. Rev Econ Dyn 11(3), 566-583.

Heaton, J. (1995). An Empirical Investigation of Asset Pricing with Temporally Dependent Preference Specifications. Econometrica 63(3), 681-717.

Heckman, J. (1974). Life Cycle Consumption and Labor Supply: An Explanation of the Relationship between Income and Consumption Over the Life Cycle. Am Econ Rev 64(1), 188-194.

Hurd, M. D. (1989). Mortality Risk and Bequest. Econometrica 57(4), 779813.

Ingersoll, Jr., J. E. (1992). Optimal Consumption and Portfolio Rules with Intertemporally Dependent Utility of Consumption. J Econ Dyn Control 16(3-4), 681-712. 
Kozicki, S. and P. Tinsley (2002). Dynamic Specifications in Optimizing Trend-Deviation Macro Models. J Econ Dyn Control 26(9-10), 15851611.

Krueger, D. and F. Perri (2006). Does Income Inequality lead to Consumption Inequality? Evidence and Theory. Rev Econ Stud 73(1), 163-193.

Lettau, M. and H. Uhlig (2000). Can Habit Formation be Reconciled with Business Cycle Facts? Rev Econ Dyn 3(1), 79-99.

Menzly, L., T. Santos, and P. Veronesi (2004). Understanding Predictability. $J$ Polit Econ 112(1), 1-46.

Merton, R. C. (1969). Lifetime Portfolio Selection Under Uncertainty: The Continuous-Time Case. Rev Econ Stat 51(3), 247-257.

Merton, R. C. (1971). Optimum Consumption and Portfolio Rules in a Continuous-Time Model. J Econ Theory 3(4), 373-413.

Meyer, D. J. and J. Meyer (2005). Relative Risk Aversion: What Do We Know? J Risk Uncertainty 31(3), 243-262.

Modigliani, F. and R. Brumberg (1954). Utility Analysis and the Consumption Function: An Interpretation of Cross-Section Data. In K. L. Kurihara (Ed.), Post Keynesian Economics. Rutgers University Press. Reprinted in Vol. 6 of "The Collected Papers of Franco Modigliani", MIT Press, 2005.

Munk, C. (2008). Portfolio and Consumption Choice with Stochastic Investment Opportunities and Habit Formation in Preferences. $J$ Econ Dyn Control 32(11), 3560-3589.

Nagatani, K. (1972). Life Cycle Saving: Theory and Fact. Am Econ Rev 62(3), 344-353.

Pijoan-Mas, J. (2007). Pricing Risk in Economies with Heterogeneous Agents and Incomplete Markets. J Eur Econ Assoc 5(5), 987-1015.

Ramsey, F. P. (1928). A Mathematical Theory of Saving. Econ J 38(152), $543-559$.

Ravina, E. (2007, November). Habit Formation and Keeping Up with the Joneses: Evidence from Micro Data. Available at SSRN: http://ssrn. $\mathrm{com} /$ abstract $=928248$.

Ryder, Harl E., J. and G. M. Heal (1973). Optimal Growth with Intertemporally Dependent Preferences. Rev Econ Stud 40(1), 1-31.

Samuelson, P. A. (1969). Lifetime Portfolio Selection by Dynamic Stochastic Programming. Rev Econ Stat 51(3), 239-246.

Thurow, L. (1969). The Optimum Lifetime Distribution of Consumption Expenditures. Am Econ Rev 59(3), 324-330. 